\title{
кУЛЬТУРОЛОГИЯ
}

DOI: 10.17805/ggz.2019.1.4

\section{Марловианский миф в современной популярной культуре*}

\author{
H. В. Захаров \\ Московский гуманитарный университет
}

В статье ставится проблема возникновения и функиионирования марловианского мифа в современной массовой культуре. Миф дает псевдоисторические интерпретачии образа Кристофера Марло. Они характерны для актуальной беллетристики, современной сиены, комиксов, кино- и телеэкранизачий. По мнению автора, к марловианскому мифу наиболее часто обращаются адепты развлекательной поп-культуры, он эксплуатируется индустрией, ориентированной на массового потребителя.

Ключевые слова: К. Марло; У. Шекспир; современники Шекспира; марловианский миф; шекспировский вопрос; массовая культура; псевдоисторический подход

\section{The Marlowe Myth in Contemporary Popular Culture}

\author{
N. V. Zakharov \\ Moscow University for the Humanities
}

The article raises the problem of the emergence and functioning of the Marlowe myth in contemporary mass culture. This myth gives pseudohistorical interpretations of the image of Christopher Marlowe. They are common to the actual fiction, modern stage, comics, cinema and TV adaptations. In the author's opinion, it is adepts of entertaining pop culture who turn to the Marlowe myth most often. The myth is exploited by the industry oriented to the mass consumer.

Keywords: C. Marlowe; W. Shakespeare; Shakespeare's contemporaries; Marlowe myth; mass culture; pseudohistorical approach

\section{ВВЕДЕНИЕ}

Проблема возникновения и культивирования марловианского мифа в современной массовой культуре имеет свою давнюю историю и тесно связа-

\footnotetext{
* Статья подготовлена в рамках проекта «Кристофер Марло и его творчество в русской и мировой культуре: междисциплинарный взгляд» при финансовой поддержке Российского фонда фундаментальных исследований (грант № 18-012-00679).

The article was prepared within the framework of the project "Christopher Marlowe and His Literary Heritage in Russian and World Culture: An Interdisciplinary Look" with financial support from the Russian Foundation for Basic Research (grant No. 18-012-00679).
} 
на с проблемой авторства или так называемого «шекспировского вопроса». С конца XIX в. такая псевдоисторическая интерпретация образа Кристофера Марло остается характерной для легкого чтива, беллетристики, для современной театральной сцены, кино- и телеэкранизаций, разного рода форм массовой литературы, включая комиксы. Не удивительно, что мифологизированный образ Марло сыскал особую популярность среди тех, кого в значительной мере привлекают не столько текст произведений драматурга, сколько его непростая и трагическая судьба. Марловианский миф чаще всего используется адептами развлекательной популярной культуры, т. е. эксплуатируется индустрией, которая ориентирована на массового потребителя. Почти всегда этот миф оказывается достаточно видоизмененным в художественных произведениях современных авторов.

В современной российской, а справедливости ради надо признать, что и в мировой культуре в целом, фигура поэта и драматурга Кристофера Марло самым тесным образом связана с его более удачливым земляком - Уильямом Шекспиром. Так уж распорядилась судьба, что трагическая жизнь Марло оборвалась слишком рано, он погиб в 29 лет. Можно, конечно, спекулировать по поводу того, каких высот достигло бы его творчество, не затей он ссоры с опасными сотрапезниками. Теперь мы можем только сожалеть об этом. Важнее попытаться понять, какой след оставил он после себя, какое место занимает его наследие в отечественной и мировой культуре сегодня.

\section{К. МАРЛО В СОВРЕМЕННОМ МАССОВОМ АНГЛО-АМЕРИКАНСКОМ КУЛЬТУРНОМ СОЗНАНИИ}

В наше время слава Марло значительно превосходит известность, скажем, его ровесников драматургов, которых принято именовать «университетскими умами» (University wits): Джона Лили (John Lyly, 1553/54?-1606), Джорджа Пиля (George Peele, 1556-1596), Томаса Лоджа (Thomas Lodge, 1558?-1625), Роберта Грина (Robert Greene, 1558?-1592), Томаса Кида (Thomas Kyd, 1558-1594) (сведений об окончании университета Кида не сохранилось см.: Дживелегов, 1943), Томаса Нэша (Thomas Nashe, 1567-1601) (см.: Луков, 2010-: Электронный ресурс). Любопытно, что все они были выходцами из среды небогатых ремесленников и священнослужителей, среди них не было аристократов, почти все, кроме Лили и Лоджа, рано скончались. Несмотря на то что их произведения полны прекрасных латинских и итальянских стихов, классическая университетская эрудиция и энциклопедизм не помогли им достичь высот драматического и поэтического мастерства, которое было уготовлено пришедшему им на смену Шекспиру.

В англо-американском массовом сознании имя Марло имеет почти культовый статус, существует даже сорт лососево-розовой розы “Christopher Marlowe”, который был назван селекционером Д. Остином в честь драматурга и поэта в 2002 г. ${ }^{1}$ Сам Марло стал персонажем литературных произведе-

\footnotetext{
${ }^{1}$ Справедливости ради, надо иметь в виду, что британский селекционер назвал сразу несколько сортов роз в честь героев шекспировских пьес: “Desdemona”, “Gentle Hermione”,
} 
ний, спектаклей, фильмов, фантастических комиксов и даже компьютерных игр. Что случилось? Почему так произошло?

Начиная с XIX в. неожиданная смерть самого успешного английского драматурга своего времени спровоцировала возникновение так называемого марловианского мифа, породив несколько версий его судьбы. Одна фантастичней другой. Все они сводятся к тому, что его мнимая смерть была всего лишь уловкой, сам он благополучно бежал из Англии на континент и продолжал писать пьесы под псевдонимом «Шекспир».

Вымышленный К. Марло довольно рано попал на страницы романтических обработок фактов о жизни реального елизаветинского драматурга. Считается, что самой ранней и почти ныне нечитаемой был роман адвоката из Огайо Уилбура Глисона Зиглера (Wilbur Gleason Zeigler) «Это был Марло: история трехвекового секрета» ("It Was Marlowe: A Story of the Secret of Three Centuries”), который был издан в 1895 г. Он и заложил фундамент марловианского мифа, выступая против тогда популярной бэконовской теории в предисловии и в комментариях своей книги (см.: Zeigler, 1895).

С тех пор список художественных произведений на тему «сбежавшего Кита Марло» значительно расширился.

Так, в пьесе Питера Уилана (Peter Whelan) «Школа ночи» (“The School of Night”, 1992), которую поставили в Королевском шекспировском театре $(R S C)$, драматурги Марло и Шекспир соперничают в борьбе за расположение Смуглой Леди, адресата сонетов. Уилан выдвигает версию ареста Кита за атеистические взгляды и его попытку осуществить побег в Венецию, но, в конце концов, для автора пьесы официальная версия его кончины оказывается более правдивой (см.: Whelan, 1992).

Обобщая вышесказанное в духе названия данного параграфа статьи, можно представить масштаб присутствия творческого наследия Марло в современном массовом англо-американском культурном сознании. Во многом оно объясняется общей тенденцией к предпочтению и подчинению авторитету Шекспира, когда Марло остается в его тени².

\section{РОМАН Э. БЁРДЖЕССА «МЕРТВЕЦ В ДЕПТФОРДЕ»}

Хотя до нас не дошло документальных свидетельств о том, что К. Марло и У. Шекспир когда-либо встречались друг с другом, не говоря уже о том, что они вместе работали над сочинением пьес (см.: Бёрджесс, 2001). Тем не менее редакторы Нового Оксфордского полного собрания сочинений Шекспира считают, что Марло участвовал в написании всех трех частей исторической пьесы «Генрих VI». Идея о том, что Марло мог выступать в каче-

\footnotetext{
“Cordelia" и даже "Falstaff". Название английской розы "Scepter'd Isle" восходит к речи Джона Гунта в «Ричарде II». За ее тонкий аромат Д. Остин получил награду от Королевского национального сообщества розоводов (см. сайт: https://rozisad.ru/?s=Шекспир).

${ }^{2}$ См., например, работы об образе К. Марло в кинематографе и на телевидении: Гайдин, 2014, 2018; Захаров, 2018.
} 
стве соавтора трилогии Шекспира и что драматурги сотрудничали, рассматривается в романе Энтони Бёрджесса «Мертвец в Дептфорде» (“А Dead Man in Deptford”, 1993) (см.: Бёрджесс, 2015). В нем Кот/Кит Марло изображен бунтарем-матерщинником, он - молодой драматург-интеллектуал, загадочный смельчак, гениальный поэт «золотого века» и профессиональный шпион на службе у королевы Елизаветы. Ярый авантюрист, он не считался с моралью, прожил полную приключений, но недолгую жизнь, которая закончилась лютой и таинственной смертью.

Совмещение документального и художественного начал, факта и вымысла в текстах биографического характера пародийных «контрбиографий» присущ Энтони Бёрджессу (Захаров, Гайдин, 2010-: Электронный ресурс). Этот прием писатель с успехом использовал еще в самом начале своей карьеры, выступив в 1964 г. с постмодернистской альтернативной биографией Шекспира, написанной в жанре романа Nothing Like the Sun: A Story of Shakespeare's Love Life (в русском переводе «Влюбленный Шекспир» — Бёрджесс, 2002). И в этом Бёрджесс не одинок: «В постмодернистской биографии усиливается игровое, пародийное начало, высвечивающее традиционные “пробелы”, пропуски в жизнеописании персонажа (“Мильтон в Америке” П. Акройда)» (Украинец, 2010а: 83). Как отметила М. А. Украинец, «биографии Акройда отличаются широким спектром сочетаний жанровых моделей: некоторые его биографии опираются только на документы и приближаются к исследованиям (например, “Жизнь Томаса Мора”), другие же допускают большую долю вымысла (“Диккенс”) или описывают то, чего заведомо никогда не существовало (“Последнее завещание Оскара Уайльда”). Писатель идет по пути идентификации себя с описываемым персонажем, что необходимо для того, чтобы заглянуть в прошлое» (Украинец, 2010b: Электронный ресурс; см. также: Ушакова, 2001; Шубина, 2009).

Так, занятие сочинительством для влюбленного Уилла, прежде всего источник дохода, ремесло, чтобы обеспечить семью. Он амбициозен, ему присуще желание обрести славу и богатство, но этим «Бёрджесс пытается не снизить портрет Шекспира, а приблизить его к человеческой натуре, ведь канонизированный образ гения мешает нам в полной мере представить его людскую жизнь» (Галахова, 2016: 1150).

В романе «Мертвец в Дептфорде», напротив, важнее линия религиозно-политических распрей, которая перемещается на театральные подмостки Лондона. Марло вовлечен в большую игру и обязан служить королеве в качестве шпиона, он изобретателен в своих ругательствах, проклятиях и богохульстве, за что в итоге и поплатился.

В отличие от Уилла Кит живет творчеством, находится в постоянном поиске, смело критикует своих менее одаренных конкурентов, высказывает всем неудобное мнение о природе творчества, политике и религии. Марло Бёрджесса - кот, гуляющий сам по себе, своенравный и вольнолюбивый: «В нем и вправду было что-то кошачье. Он щурил свои зеленые глаза и умел ускользать от пристального взгляда, как это делают кошки, когда испытывал либо страх, либо агрессию, вызванную опять же или страхом, или чувством 
стыда. Даже во время полового акта его глаза оставались безучастными, по крайней мере в большинстве случаев. Вполне может статься, что, хотя гомосексуальные отношения, как правило, исключают общение при помощи взглядов, они допускают наличие хотя бы временного союза двух сердец. Правда, относительно сердца Кита я не могу быть ни в чем уверен. Могу только предполагать, и я предполагаю. Прибавлю, что его лицо тоже напоминало кошку: широкий в ноздрях нос, холодный и влажный, однако подбородок - всегда горячий - выдавался вперед. Что касается верхней губы, она была длинной, как у жителей Кента. Усы (с позволения сказать) были и впрямь кошачьи и совершенно непохожи на настоящие мужские усы; бородка тоже жидкая. Было ясно, что она никогда не станет густой, как у зрелого мужчины. Зато урожай волос на голове был обильный, хотя и не в виде зерна. Позвольте мне сравнить его голову со стогом сена. В сухую погоду, которая предвещает гром, он выглядит угрожающе - готов загореться от удара молнии. Однако, созерцая его обнаженное тело, я отметил, что волос на нем было мало: редкая шерстка, как после дождичка в четверг. У него было гладкое тело, красивая фигура и плоский живот. Готов поклясться: это неправда, что у него был лишний сосок. 8-9).

Он ел мало, зато много пил и часто страдал рвотой» (Бёрджесс, 2015:

Любовная линия в романе Бёрджеса воплотилась в нежных отношениях Кита с Томасом Уолсингемом, юношей из знатной семьи, но менее явно, нежели во «Влюбленном Шекспире», поскольку носит скорее платонический характер, что было вполне свойственно Англии времен правления Елизаветы I, ведь «проповедь безбрачия и гомосексуализма парадоксально сочеталась с царившим в то время культом Королевы-девственницы. Во всем драматургическом наследии Марло можно отыскать лишь одну любовную линию — историю Эдуарда II и его фаворита Гавестона (“Дидона” написана вместе с Томасом Нэшем)» (Львов, 2016: Электронный ресурс).

Роман о Кристофере Марло вышел в 1993 г. и стал «отчасти и заказной работой» (там же), посвященной 400-летию смерти поэта и драматурга, отчасти итогом всей творческой и научной карьеры Бёрджесса. Книга вышла уже после смерти автора: «Теперь, когда отмечается четыреста лет со дня убийства Марло в 1593 году, я хочу принести дань уважения великому писателю. $<\ldots>$ Возможно, Шекспир и затмил Марло, но он не в состоянии вытеснить его или занять его место. Неповторимый голос продолжает звучать» (Бёрджесс, 2015: 378-379).

\section{К. МАРЛО В ДРУГИХ \\ ХУДОЖЕСТВЕННЫХ ПРОИЗВЕДЕНИЯХ}

Ю. М. Нагибин в рассказе «Надгробие Кристофера Марло» (Нагибин, 1983) разработал одну из наиболее поэтичных версий: почитатель таланта Марло убивает его, совершая геростратов подвиг, таким образом добиваясь, чтобы в надгробной надписи было запечатлено его имя (пусть в роли убийцы) рядом с именем его кумира. 
Кроме «Мертвеца в Дептфорде» Э. Бёрджесса в 1993 г., в 400-ю годовщину смерти Марло, был опубликован шпионский роман «Кристофер, или Месть Тома Кида» (“Christoferus, or, Tom Kyd's Revenge”) известного поклонника Шекспира и Сервантеса (автор романа "Shakespeare's Don Quixote”, 2011), драматурга, сценариста и актера Робина Чепмена (Robin Chapman) (Chapman, 1993; см.: Nicholl, 2013: Электронный ресурс). Не удивительно, что бывший президент Марловианского общества (The Marlowe Society) Кембриджского университета взялся за сочинительство увлекательной и живой истории о чумных событиях Англии 1593 г., когда агенты секретной службы королевы Елизаветы арестовали Т. Кида с целью получить показания против его друга К. Марло. После трех дней допросов и пыток он подписал бумаги, обвиняющие друга в богохульстве и распутстве.

Вымышленная версия последних похождений К. Марло также изложена шотландской детективной писательницей Луизой Уэлш (Louise Welsh) в новелле «Тамерлан должен умереть» (“Tamburlaine Must Die”; Welsh, 2004; см.: Hamilos, 2005: Электронный ресурс). Как и многое из того, что написано автором, проживающем в Глазго, городе с самым высоким уровнем убийств в Европе, марловианская мрачноватая готическая фантастика Уэлш повествует о надуманной, а не реконструированной истории, о сексе и неприглядной правде. В ней Лондон - город, живущий на нерве религиозной борьбы. Выражение собственных взглядов преследуется сверхдержавным елизаветинским государством, во всем обвиняют людей иного вероисповедания, представителей эмигрантской среды. Жизнь людей находится под постоянной угрозой распространения чумы и начала новых войн, а также подвергается опасности со стороны религиозных фанатиков, заговорщиков и шпионов. Марло - часть этой опасной игры, и его бурная жизнь в Лондоне протекает в трактирах и борделях, странные его отношения с покровителем Уолсингемом только ускоряет развитие действия этого триллера.

Сама писательница считает, что все эти темы достаточно актуальны и для XXI в. Ее понимание истории и исторических произведений состоит в том, что они должны не только оживлять прошлое, но и быть созвучны современности, «должны иметь резонанс сегодня» ("I do believe historical books should have a resonance now”) (цит. по: ibid).

Как это принято в квазиисторической литературе и в подобного рода телевизионных сериалах («Тюдоры», «Уилл» и др.), Уэлш не избежала того, что за рубежом принято называть «поп-порнографизацией» (см.: Kasarda, 2013). Хотя на страницах «Тамерлана» эротики не так много, автор симпатизирует бисексуальности и атеизму своего героя, восхищается его безрассудностью, приписывает ему свои взгляды на религию: “I guess it's hard to disentangle your own views about it. I instinctively thought there is no God. There is no philosophical contract for me. It's a huge delusion to believe in God. To break that kind of delusion in that era was amazingly brave or foolhardy” (цит. по: Hamilos, 2005: Электронный ресурс).

Противоречивость натуры Марло привлекает Уэлш поразительной способностью к самовыражению в слове, одновременно и страстной, и лирич- 
ной. Он склонен к насилию и был обвинен в убийстве: “That contradiction is part of the attraction. We all know people who work really hard and party really hard, and Marlowe is like that” (цит. по: ibid).

Ее «Тамерлан должен умереть» является одним из образчиков псевдоисторического чтива, которое в мягкой обложке можно приобрести в Кэнонгейте, небольшом районе Старого города Эдинбурга, за каких-нибудь 7 фунтов стерлингов.

Стихотворный роман «Архив Марло» (“The Marlowe Papers”; Barber, 2012) посвятила Киту Роз Барбер (Ros Barber, биолог по образованию, PhD, ныне преподаватель кафедры английского языка и сравнительного литературоведения Голдсмитского колледжа). Напомним, что она же является автором первого антишекспировского МООКа «Введение в проблему: кто писал за Шекспира?» (Introduction ... , 2018: Электронный ресурс), который стартовал на платформе Coursera в 2018 г. (Захаров, Макаров, 2018: Электронный ресурс). Ее повторение мифа про выжившего драматурга банально. Скрываясь от суда за ересь, Марло выбирает роль изгнанника, который создает свои произведения на континенте и передает пьесы через купцов. Единственное, что, по мнению автора книги «Расплата: убийство Кристофера Марло» (Nicholl, 1992) Чарльза Николла (Charles Nicholl), является у Барбер уникальным - это ее поэтический дар и смелость следовать давно забытому жанру романа в стихах: “It is also a brave one, given that the public's appetite for versenovels has diminished rather drastically since their 19th-century heyday, when writers of the stature of Byron, Browning and Pushkin rattled them off with aplomb” (Nicholl, 2013: Электронный ресурс).

\section{ЗАКЛЮЧЕНИЕ}

Как уже отмечалось выше марловианский миф и реальная историческая личность Кристофера Марло почти всегда связывается с фигурой Уильяма Шекспира, эксплуатация их образов и творческого наследия, скорее всего, никогда не достигнет равенства в поп-индустрии. Об этом красноречиво говорит хотя бы один маленький пример: ранее в Интернете упоминалась история про настольную игру с миниатюрными фигурками по произведениям Марло (см. запись в блоге автора сценария игры Джеффа Василески / Jeff Wasileski — Bogdanwaz, 2018: Электронный peсурс). В юбилейном 2016 г. подобная игра была разыграна по произведениям Шекспира со многими теми же участниками. По сценарию «Полного собрания сочинений Шекспира (в сокращении)» жители небольшой английской деревушки под выдуманным названием Nether Tiddlington решили разбогатеть на культе бессмертного Барда и учредить ежегодный Шекспировский фестиваль, дабы увеличить доходы от туризма. Ничего лучше не смогли придумать его устроители, нежели провести фестиваль на древнем оккультном месте друидов за населенным пунктом. В этой альтернативной вселенной произведения Шекспира - не плод фантазии автора, а реальность. Более того она существует не только в известных сочинениях ренессансного автора, но и в различных современных адаптациях. Так, местные жители подверглись атаке драматургической ма- 
гии, столкнулись с ордами захватчиков в виде известных актеров: Кеннета Браны (Kenneth Branagh) в роли Гамлета, с гестаповским Ричардом Третьим Иэна МакКеллена (Ian McKellan), с Юлием Цезарем Марлона Брандо (Marlon Brando), патриотом Генрихом Пятым Лоуренса Оливье (Laurence Olivier), капризным Ромео Леонардо ДиКаприо (Leonardo Di Caprio) и яростным Макбетом Майкла Фассбендера (Michael Fassbender).

Главной целью захватчиков стало возвращение героинь Шекспира (Офелия, Катарина, Дездемона, Джульетта, леди Макбет и Клеопатра), которых собрала в приюте жертв домашнего насилия феминистка Портия Бёрбедж, защитница их прав (см.: Bogdanwaz, 2016: Электронный ресурс). Не удивительно, что эта масштабная игра по мотивам шекспировских адаптаций собрала за одним столом более 20 человек против 11 игроков по произведениям Марло.

Проблема возникновения и функционирования марловианского мифа в современной массовой культуре ставится и обсуждается в русле тезаурусного подхода, теоретические основы которого много лет разрабатываются научной школой Института фундаментальных и прикладных исследований Московского гуманитарного университета (см.: Луков, Луков, 2008, 2013). Используя тезаурусный анализ, можно описать механизм того, как миф порождает псевдоисторические интерпретации образа Марло, почему они популярны в массовой культуре: беллетристике, современном театре, комиксах, кино- и телеэкранизациях и т. д. Не случайно, что к марловианскому мифу наиболее часто обращаются адепты поп-культуры, журналисты, независимые исследователи, краеведы и прочие энтузиасты, приверженцы вымышленной идеи, что К. Марло избежал гибели и продолжал творить в изгнании под псевдонимом «Шекспир». Некоторые беллетристы идут еще дальше и штампуют сочинения, в которых не гнушаются приписать смерть Кита на счет самого Уильяма. Все они эксплуатируют миф о жизни и творчестве драматурга, ориентированный на массового потребителя.

До сих пор о быстро развивавшейся «марлосфере» можно было говорить в контексте шекспиросферы (см.: Луков и др., 2012: Электронный ресурс; Лисович, Макаров, 2014; Захаров, 2015, 2016; Макаров, Захаров, Гайдин, 2016). И хотя их модели практически идентичны, но их значение в постиндустриальном информационном обществе не соизмеримо. Даже сейчас в России, если кто и играет Шекспира на сцене, то эти постановки все-таки чаще всего имеют не массовый, а элитарный характер. Они обусловлены амбициями режиссеров, актеров, сценографов, композиторов и т. д., их потребностью «школы» и желанием взять «уроки» у Шекспира и своих предшественников. А что же с Марло? Если о таком явлении, как «русский Шекспир», мы можем говорить не только в связи с тем, что каждый сезон на московской сцене идут обычно не менее десяти «Гамлетов», но и в связи с переводческой практикой и развитием книжной индустрии, то можем ли мы возвестить о появлении в отечественной культуре феномена «русского Марло»? Пока нет. 
В любом случае, необходимо провести комплексное исследование этой темы, изучить ее связи с шекспиросферой. Актуальность марловианского мифа возникла не в связи с юбилейными датами со дня рождения или смерти К. Марло, а в результате устойчивого интереса людей к творчеству У. Шекспира и других елизаветинцев.

\section{СПИСОК ЛИТЕРАТУРЫ}

Бёрджесс, Э. (2001) Шекспир. Гений и его эпоха. М. : Центрполиграф. $383 \mathrm{c}$.

Бёрджесс, Э. (2002) Влюбленный Шекспир. М. : Центрполиграф. 332 с.

Бёрджесс, Э. (2015) Мертвец в Дептфорде / пер. с англ. Л. Иотковской. М. : АСТ. 384 с. (Зарубежная классика).

Гайдин, Б. Н. (2014) Шекспиросфера в современном кино: постановка проблемы [Электронный ресурс] // Информационный гуманитарный портал «Знание. Понимание. Умение». № 4 (июль - август). URL: http://www.zpujournal.ru/e-zpu/2014/4/Gaydin_Shakespearean-Sphere-Cinema/ [архивировано в WaybackMachine] (дата обращения: 13.12.2018).

Гайдин, Б. Н. (2018) К. Марло в кино и на телевидении: основные тенденции рецепции [Электронный ресурс] // Горизонты гуманитарного знания. № 6. C. 44-60. URL: http://journals.mosgu.ru/ggz/article/view/892 (дата обращения: 13.12.2018). DOI: 10.17805/ggz.2018.6.4

Галахова, А. А. (2016) Альтернативная биография Уильяма Шекспира и Кристофера Марло в елизаветинской дилогии Энтони Бёрджесса [Электронный ресурс] // Молодой ученый. № 7 (111). C. 1149-1152. URL: https://moluch.ru/archive/111/27856/ [архивировано в WaybackMachine] (дата обращения: 13.12.2018).

Дживелегов, А. К. (1943) «Университетские умы» // История английской литературы : в 3 т. М. ; Л. : Изд-во Академии наук СССР. Т. 1. Вып. І. 382, [2] c. C. 341-361.

Захаров, Н. В. (2015) Шекспир между фактом и воображением: виртуальная шекспиросфера и массовые открытые онлайн-курсы (МООК) // Воображение и факт в конструировании художественных и виртуальных миров шекспировской Англии : сб. науч. статей / отв. ред. и сост. И. И. Лисович ; ред.: В. С. Макаров, Б. Н. Гайдин. М. : Изд-во Моск. гуманит. ун-та. 176 с. C. $157-170$.

Захаров, Н. В. (2016) Портретные изображения Шекспира в виртуальной шекспиросфере // Знание. Понимание. Умение. № 1. С. 263-270. DOI: 10.17805/zpu.2016.1.22

Захаров, Н. В. (2019) Образы Марло и Шекспира в современной киноиндустрии // Знание. Понимание. Умение. № 1. (В печати).

Захаров, Н. В., Гайдин, Б. Н. (2010-) Бёрджесс Энтони [Электронный pecypc] // Электронная энциклопедия «Мир Шекспира». URL: http://www. world-shake.ru/ru/Encyclopaedia/3664.html [архивировано в WaybackMachine] (дата обращения: 13.12.2018). 
Захаров, Н. В., Макаров, В. С. (2018) Первый антишекспировский МООК стартовал на платформе Coursera [Электронный ресурс] // Информационнаяисследовательская база данных «Современники Шекспира». 22 февраля. URL: http://around-shake.ru/news/5118.html [архивировано в WaybackMachine] (дата обращения: 13.12.2018).

Лисович, И. И., Макаров, В. С. (2014) Научно-исследовательский проект «Виртуальная шекспиросфера: трансформации шекспировского мифа в современной культуре» // Знание. Понимание. Умение. № 2. С. 264-282.

Луков, В. А. и др. (2012) Шекспиросфера (Шекспир, его современники, его эпоха в культуре повседневности) / В. А. Луков, Н. В. Захаров, Вл. А. Луков, Б. Н. Гайдин [Электронный ресурс] // Информационный гуманитарный портал «Знание. Понимание. Умение». № 3 (май - июнь). URL: http://zpu-journal.ru/e-zpu/2012/3/Lukov Zakharov Lukov Gaydin Shakespearesphere/ [архивировано в WaybackMachine] (дата обращения: 13.12.2018).

Луков, В. А., Луков, Вл. А. (2008) Тезаурусы: Субъектная организация гуманитарного знания. М. : Изд-во Нац. ин-та бизнеса. 784 с.

Луков, В. А., Луков, Вл. А. (2013) Тезаурусы II: Тезаурусный подход к пониманию человека и его мира. М. : Изд-во Нац. ин-та бизнеса. 640 с.

Луков, Вл. А. (2010-) Английская ренессансная драматургия «университетских умов» - предшественников Шекспира [Электронный ресурс] // Электронная энциклопедия «Мир Шекспира». URL: http://www.world-shake. ru/ru/Encyclopaedia/4136.html [архивировано в WaybackMachine] (дата обращения: 13.12.2018).

Львов, К. (2016) «Добро и разум изгнаны за дверь» [Электронный ресурс] // Радио Свобода. 11 сентября. URL: https://www.svoboda.org/a/2797 0305.html [архивировано в WaybackMachine] (дата обращения: 13.12.2018).

Макаров, В. С., Захаров, Н. В., Гайдин, Б. Н. (2016) Шекспиросфера в год четырехсотлетия бессмертия поэта // Знание. Понимание. Умение. № 4. С. 275302. DOI: $10.17805 /$ zpu.2016.4.24

Нагибин, Ю. М. (1983) Надгробие Кристофера Марло : рассказ // Нагибин Ю. М. Царскосельское утро. М. : Советский писатель. 528 с. С. 216-228.

Украинец, М. А. (2010а) Проблема внутрижанровой типологии произведений англоязычной биографической прозы // Вестник Московского государственного областного университета. Серия: Лингвистика. № 1. С. 82-85.

Украинец, М. А. (2010b) О некоторых стилистических особенностях биографий Питера Акройда (на материале биографий «Жизнь Томаса Мора» и «Диккенс») [Электронный ресурс] // Мат. Междунар. молодежного науч. форума «Ломоносов-2010» / отв. ред. И. А. Алешковский, П. Н. Костылев, А. И. Андреев и др. М. : МАКС Пресс. URL: https://lomonosov-msu.ru/archive/ Lomonosov_2010/24-9.pdf [архивировано в WaybackMachine] (дата обращения: 13.12.2018).

Ушакова, Е. В. (2001) Литературная биография как жанр в творчестве П. Акройда : дис. ... канд. филол. наук : 10.01.03. М. : МГУ. 195 с.

Шубина, А. В. (2009) Проблема биографического жанра в творчестве Питера Акройда : автореф. дис. ... канд. филол. наук. СПб. 30 с. 
Barber, R. (2012) The Marlowe papers : A novel in verse. L. : Sceptre. xiv, 445 p.

Bogdanwaz [Wasileski, J.] (2016) The complete works of Shakespeare (abridged) — The village of Nether Tiddlington [Электронный ресурс] // O My Ruritania! April 25. URL: http://bogdanwaz.blogspot.com/2016/04/the-completeworks-of-shakespeare_25.html [архивировано в WaybackMachine] (дата обращения: 13.12.2018).

Bogdanwaz [Wasileski, J.] (2018) Cold Wars 2018 game — A Dead Man in Deptford [Электронный pecypc] // O My Ruritania! March 6. URL: http://bogdanwaz.blogspot.com/2018/03/cold-wars-2018-game.html [архивировано в WaybackMachine] (дата обращения: 13.12.2018).

Chapman, R. (1993) Christoferus, or, Tom Kyd’s revenge. L. : Sinclair-Stevenson. $393 \mathrm{p}$.

Hamilos, P. (2005) Capital encounter : interview / P. Hamilos, L. Welsh [Электронный pecypc] // The Guardian. August 5. URL: https://www. theguardian.com/books/2005/aug/05/fiction.paulhamilos [архивировано в WaybackMachine] (дата обращения: 13.12.2018).

Introduction to Who Wrote Shakespeare [Электронный pecypc] // Coursera. URL: https://www.coursera.org/learn/shakespeare/ [архивировано в WaybackMachine] (дата обращения: 13.12.2018).

Kasarda, M. (2013) Pop-pornografizácia: výpredaj zlacnenej erotiky v populárnej literatúre = Pop-pornographysation: on sale: erotica on pop-literature // Sex lži a video: aktuálne otázky — mediálnej kultúry : zborník z medzinárodnej vedeckej konferencie "Megatrendy a médiá 2013: kultivácia médií — možnosti a bariéry” / editori zborníka: D. Petranová, H. Pravdová, M. Solík. Trnava : Fakulta masmediálnej komunikácie UCM. S. 172-181.

Nicholl, C. (1992) The reckoning: The murder of Christopher Marlowe. N. Y. : Harcourt Brace. 413 p.

Nicholl, C. (2013) Exiting the stage. 'The Marlowe Papers,' by Ros Barber [Электронный ресурс] // The New York Times. January 25. URL: https://www. nytimes.com/2013/01/27/books/review/the-marlowe-papers-by-ros-barber.html [архивировано в WaybackMachine] (дата обращения: 13.12.2018).

Welsh, L. (2004) Tamburlaine must die. Edinburgh : Canongate. 160 p.

Whelan, P. (1992) The school of night. L. : Warner Chappell Plays. 99 p.

Zeigler, W. G. (1895) It was Marlowe: A story of the secret of three centuries. Chicago : Donohue, Henneberry \& Company. 3 preliminary leaves, v-xi, 13310 p. URL: https://archive.org/details/itwasmarloweast00zeiggoog/ (дата обращения: 13.12.2018).

Дата поступления: 19.12.2018 2.

\section{REFERENCES}

Burgess, A. (2001) Shekspir. Genii i ego epokha [Shakespeare. Genius and his age]. Moscow : Tsentrpoligraf Publ. 383 p. (In Russ.). 
Burgess, A. (2002) Vliublennyi Shekspir [Nothing Like the Sun: A Story of Shakespeare's Love Life]. Moscow : Tsentrpoligraf Publ. 332 p. (In Russ.).

Burgess, A. (2015) Mertvets v Deptforde [Dead man in Deptford] / transl. from English by L. Iotkovskaia. Moscow : AST Publ. 384 p. (Zarubezhnaia klassika / Foreign Classics). (In Russ.).

Gaydin, B. N. (2014) Shekspirosfera v sovremennom kino: postanovka problemy [The Shakespearean sphere in contemporary cinema: The problem definition]. Informatsionnyi gumanitarnyi portal "Znanie. Ponimanie. Umenie", no. 4 (July — August). [online] Available at: http://www.zpu-journal.ru/e-zpu/2014/4/ Gaydin_Shakespearean-Sphere-Cinema/ [archived in WaybackMachine] (accessed 13.12.2018). (In Russ.).

Gaydin, B. N. (2018) K. Marlo v kino i na televidenii: osnovnye tendentsii retseptsii [C. Marlowe on film and television: Main trends of reception]. Gorizonty gumanitarnogo znaniia, no. 6, pp. 44-60. [online] Available at: http://journals. mosgu.ru/ggz/article/view/892 (accessed 13.12.2018). DOI: 10.17805/ggz.2018. $\underline{6.4}$ (In Russ.).

Galakhova, A. A. (2016) Al'ternativnaia biografiia Uil'iama Shekspira i Kristofera Marlo v elizavetinskoi dilogii Entoni Berdzhessa [Alternative biographies of William Shakespeare and Christopher Marlowe in Anthony Burgess' Elizabethan dilogy]. Molodoi uchenyi, no. 7 (111), pp. 1149-1152. [online] Available at: https://moluch.ru/archive/111/27856/ [archived in WaybackMachine] (accessed 13.12.2018). (In Russ.).

Dzhivelegov, A. K. (1943) «Universitetskie umy» [“University Wits”]. In: Istoriia angliiskoi literatury [History of English literature] : in 3 vols. Moscow ; Leningrad : USSR Academy of Sciences Publishing House. Vol. 1. Issue I. 382, [2] p. Pp. 341-361. (In Russ.).

Zakharov, N. V. (2015) Shekspir mezhdu faktom i voobrazheniem: virtual'naia shekspirosfera i massovye otkrytye onlain-kursy (MOOK) [Shakespeare between fact and imagination: Virtual Shakespearean sphere and massive open online courses (MOOCs)]. In: Voobrazhenie i fakt v konstruirovanii khudozhestvennykh $i$ virtual'nykh mirov shekspirovskoi Anglii [Imagination and fact in constructing artistic and virtual worlds of Shakespeare's England] : A collection of articles / ed. and comp. by I. I. Lisovich ; ed. by V. S. Makarov and B. N. Gaydin. Moscow : Moscow University for the Humanities Publ. 176 p. Pp. 157-170. (In Russ.).

Zakharov, N. V. (2016) Portretnye izobrazheniia Shekspira v virtual'noi shekspirosfere [Portraits of Shakespeare in the virtual Shakespearean sphere]. Znanie. Ponimanie. Umenie, no. 1, pp. 263-270. DOI: 10.17805/zpu.2016.1.22 (In Russ.).

Zakharov, N. V. (2019) Obrazy Marlo i Shekspira v sovremennoi kinoindustrii [Images of Marlowe and Shakespeare in modern film industry]. Znanie. Ponimanie. Umenie, no. 1. (Forthcoming). (In Russ.).

Zakharov, N. V. and Gaydin, B. N. (2010-) Berdzhess Entoni [Burgess Anthony]. Elektronnaia entsiklopediia «Mir Shekspira» [Electronic encylopaedia "The World of Shakespeare"]. [online] Available at: http://www.world- 
shake.ru/ru/Encyclopaedia/3664.html [archived in WaybackMachine] (accessed 13.12.2018). (In Russ.).

Zakharov, N. V. and Makarov, V. S. (2018) Pervyi antishekspirovskii MOOK startoval na platforme Coursera [First anti-Shakespearean MOOC started at Coursera platform]. Informatsionnaia-issledovatel'skaia baza dannykh «Sovremenniki Shekspira» [Information and Research Database "Shakespeare's Contemporaries"], February 22. [online] Available at: http://around-shake.ru/ news/5118.html [archived in WaybackMachine] (accessed 13.12.2018). (In Russ.).

Lisovich, I. I. and Makarov, V. S. (2014) Nauchno-issledovatel'skii proekt «Virtual'naia shekspirosfera: transformatsii shekspirovskogo mifa v sovremennoi kul'ture» [Research project "Virtual Shakespearean sphere: Transformations of Shakespearian myth in modern culture”]. Znanie. Ponimanie. Umenie, no. 2, pp. 264-282. (In Russ.).

Lukov, V. A. et al. (2012) Shekspirosfera (Shekspir, ego sovremenniki, ego epokha v kul'ture povsednevnosti) [The Shakespearean sphere (Shakespeare, his contemporaries, his age in the culture of everyday life)] / V. A. Lukov, N. V. Zakharov, Vl. A. Lukov and B. N. Gaydin. Informatsionnyi gumanitarnyi portal "Znanie. Ponimanie. Umenie", no. 3 (May - June). [online] Available at: http://zpu-journal.ru/e-zpu/2012/3/Lukov Zakharov Lukov Gaydin Shakespearesphere/ [archived in WaybackMachine] (accessed 13.12.2018). (In Russ.).

Lukov, V. A. and Lukov, Vl. A. (2008) Tezaurusy: Sub"ektnaia organizatsiia gumanitarnogo znaniia [Thesauri: Subjective organization of humanities knowledge]. Moscow : The National Institute of Business Publ. 784 p. (In Russ.).

Lukov, V. A. and Lukov, Vl. A. (2013) Tezaurusy II: Tezaurusnyi podkhod $k$ ponimaniiu cheloveka i ego mira [Thesauri II: The thesaurus approach to the conceptualization of the person and his/her world]. Moscow : The National Institute of Business Publ. 640 p. (In Russ.).

Lukov, Vl. A. (2010-) Angliiskaia renessansnaia dramaturgiia «universitetskikh umov» - predshestvennikov Shekspira [English Renaissance drama of the "University Wits" - Shakespeare's predecessors]. Elektronnaia entsiklopediia "Mir Shekspira» [Electronic encylopaedia "The World of Shakespeare”]. [online] Available at: http://www.world-shake.ru/ru/Encyclopaedia/4136.html [archived in WaybackMachine] (accessed 13.12.2018). (In Russ.).

Lvov, K. (2016) «Dobro i razum izgnany za dver'» [“The good and reason have been expelled outside"]. Radio Svoboda, September 11. [online] Available at: https://www.svoboda.org/a/27970305.html [archived in WaybackMachine] (accessed 13.12.2018). (In Russ.).

Makarov, V. S., Zakharov, N. V. and Gaydin, B. N. (2016) Shekspirosfera $\mathrm{v}$ god chetyrekhsotletiia bessmertiia poeta [The Shakespearean sphere in the year of the 400th anniversary of poet's immortality]. Znanie. Ponimanie. Umenie, no. 4, pp. 275-302. DOI: 10.17805/zpu.2016.4.24 (In Russ.).

Nagibin, Yu. M. (1983) Nadgrobie Kristofera Marlo [Christopher Marlowe's tomb] : A short story. In: Nagibin, Yu. M. Tsarskosel'skoe utro [Morning in Tsarskoye Selo]. Moscow : Sovetskii pisatel' Publ. 528 p. Pp. 216-228. (In Russ.). 
Ukrainets, M. A. (2010a) Problema vnutrizhanrovoi tipologii proizvedenii angloiazychnoi biograficheskoi prozy [The problem of making a genre typology of English biographical prose]. Vestnik Moskovskogo gosudarstvennogo oblastnogo universiteta. Seriia: Lingvistika, no. 1, pp. 82-85. (In Russ.).

Ukrainets, M. A. (2010b) O nekotorykh stilisticheskikh osobennostiakh biografii Pitera Akroida (na materiale biografii «Zhizn' Tomasa Mora» i «Dikkens») [On some stylistic features of Peter Ackroyd's biography (A case study of "The Life of Thomas Moore" and "Dickens"]. In: Materialy Mezhdunarodnogo molodezhnogo nauchnogo foruma «Lomonosov-2010» [Proceedings of the International youth scientific forum "Lomonosov-2010"] / ed. by I. A. Aleshkovskii, P. N. Kostylev, A. I. Andreev et al. Moscow : MAKS Press. [online] Available at: https://lomonosov-msu.ru/archive/Lomonosov_2010/24-9.pdf [archived in WaybackMachine] (accessed 13.12.2018). (In Russ.).

Ushakova, E. V. (2001) Literaturnaia biografiia kak zhanr v tvorchestve P. Akroida [Literary biography as a genre in P. Ackroyd's creative works] : Dissertation ... Candidate of Philology : 10.01.03. Moscow : Moscow State University Publ. 195 p. (In Russ.).

Shubina, A. V. (2009) Problema biograficheskogo zhanra $v$ tvorchestve Pitera Akroida [The problem of biographical genre in Peter Ackroyd's creative works] : Abstract of the dissertation ... Candidate of Philology. St. Petersburg. 30 p. (In Russ.).

Barber, R. (2012) The Marlowe papers : A novel in verse. London : Sceptre. xiv, 445 p.

Bogdanwaz [Wasileski, J.] (2016) The complete works of Shakespeare (abridged) - The village of Nether Tiddlington. O My Ruritania!, April 25. [online] Available at: http://bogdanwaz.blogspot.com/2016/04/the-complete-works -of-shakespeare_25.html [archived in WaybackMachine] (accessed 13.12.2018).

Bogdanwaz [Wasileski, J.] (2018) Cold Wars 2018 game - A Dead Man in Deptford. O My Ruritania!, March 6. [online] Available at: http:// bogdanwaz.blogspot.com/2018/03/cold-wars-2018-game.html [archived in WaybackMachine] (accessed 13.12.2018).

Chapman, R. (1993) Christoferus, or, Tom Kyd's revenge. London : Sinclair-Stevenson. $393 \mathrm{p}$.

Hamilos, P. (2005) Capital encounter : interview / P. Hamilos, L. Welsh. The Guardian, August 5. [online] Available at: https://www.theguardian.com/ books/2005/aug/05/fiction.paulhamilos [archived in WaybackMachine] (accessed 13.12.2018).

Introduction to Who Wrote Shakespeare. Coursera [online] Available at: https://www.coursera.org/learn/shakespeare/ [archived in WaybackMachine] (accessed 13.12.2018).

Kasarda, M. (2013) Pop-pornografizácia : výpredaj zlacnenej erotiky v populárnej literatúre [Pop-pornographysation: On sale: Erotica on pop-literature]. In: Sex lži a video : aktuálne otázky mediálnej kultúry Pop-pornographysation : on sale: erotica on pop-literature]. In: Sex lži a video: aktuálne otázky - mediálnej kultúry [Sex, lies and video: Actual issues of media culture. Megatrends and $\mathrm{Me}$ - 
dia] : Proceedings of the International conference "Megatrends and Media 2013" / ed. by D. Petranová, H. Pravdová and M. Solík. Trnava : Fakulta masmediálnej komunikácie UCM. Pp. 172-181. (In Slovakian).

Nicholl, C. (1992) The reckoning: The murder of Christopher Marlowe. New York : Harcourt Brace. 413 p.

Nicholl, C. (2013) Exiting the stage. 'The Marlowe Papers,' by Ros Barber. The New York Times, January 25. [online] Available at: https://www.nytimes.com/ 2013/01/27/books/review/the-marlowe-papers-by-ros-barber.html [archived in WaybackMachine] (accessed 13.12.2018).

Welsh, L. (2004) Tamburlaine must die. Edinburgh : Canongate. 160 p.

Whelan, P. (1992) The school of night. London : Warner Chappell Plays. 99 p.

Zeigler, W. G. (1895) It was Marlowe: A story of the secret of three centuries. Chicago : Donohue, Henneberry \& Company. 3 preliminary leaves, v-xi, 13310 p. [online] Available at: https://archive.org/details/itwasmarloweast00zeig goog/ (accessed 13.12.2018).

Submission date: 19.12.2018.

Захаров Николай Владимирович - доктор философии (PhD), кандидат филологических наук, директор Шекспировского центра Института фундаментальных и прикладных исследований Московского гуманитарного университета, академик Международной академии наук (IAS, Инсбрук, Австрия), ученый секретарь Шекспировской комиссии РАН. Адрес: 111395, Россия, г. Москва, ул. Юности, 5, корп. 6. Тел.: +7 (499) 374-75-95. Эл. адрес: nikoltine@yandex.ru

Zakharov Nikolay Vladimirovich, PhD, Candidate of Philology; Director, Shakespeare Center, Institute of Fundamental and Applied Studies, Moscow University for the Humanities; full member, International Academy of Science (Innsbruck, Austria); Academic Secretary, Shakespeare Committee, Russian Academy of Sciences. Postal address: Bldg. 6, 5 Yunosti St., 111395 Moscow, Russian Federation. Tel.: +7 (499) 374-75-95. E-mail: nikoltine@yandex.ru

\section{Для циитирования:}

Захаров H. B. Марловианский миф в современной популярной культуре [Электронный ресурс] // Горизонты гуманитарного знания. 2019. № 1. С. 7488. URL: http://journals.mosgu.ru/ggz/article/view/952 (дата обращения: дд.мм. гггг). DOI: 10.17805/ggz.2019.1.4 